\title{
Distinct modulation of chemokine expression patterns in human monocyte-derived dendritic cells by prostaglandin $\mathrm{E}_{2}$
}

\author{
Markus Bruckner ${ }^{\mathrm{a}}$, Denise Dickel ${ }^{\mathrm{a}}$, Eva Singer ${ }^{\mathrm{b}}$, Daniel F. Legler ${ }^{\mathrm{a}, *}$ \\ a Biotechnology Institute Thurgau (BITg) at the University of Konstanz, Kreuzlingen, Switzerland \\ ${ }^{\mathrm{b}}$ Klinikum Konstanz, Konstanz, Germany
}

Keywords:

Human monocyte-derived dendritic cells Chemokines

Prostaglandin $\mathrm{E}_{2}$

\begin{abstract}
A B S T R A C T
Dendritic cells (DCs) are key in regulating immune responses. DCs reside in tissues facing the environ ment and sample their surrounding for pathogens. Upon pathogen encounter, DCs mature and migrate into secondary lymphoid organs. Distinct maturation signals dictate the ability of DCs to produce distinct patterns of chemokines that orchestrate immunity. Prostaglandin $\mathrm{E}_{2}\left(\mathrm{PGE}_{2}\right)$ is produced during inflamma tion and modulates $\mathrm{DC}$ functions. We demonstrate that $\mathrm{PGE}_{2}$ modulates distinct chemokine expression patterns of human monocyte derived (Mo) DCs upon maturation with various stimuli. $\mathrm{PGE}_{2}$ dampened early production of the inflammatory chemokines CCL2, CCL4, CCL5 and attenuated the expression of the $\mathrm{T}$ cell attractant CXCL10. In contrast, PGE 2 enhanced CXCL8 production early during maturation, whereas CXCL16 levels were continuously elevated, contributing to innate immune cell recruitment. Moreover, $\mathrm{PGE}_{2}$ induces transcription of the homeostatic chemokines CCL17 and CCL22. Finally, mature MoDCs produced the homing chemokine CCL19 and its expression was down regulated by PGE .
\end{abstract}

\section{Introduction}

Dendritic cells (DCs) are the most potent antigen presenting cells (APCs) capable of inducing adaptive immunity or tolerance $[1,2]$. In their immature state, DCs are strategically located at routes of pathogen entry and constantly scan the surrounding environment for antigens derived from invading pathogens [3]. Upon antigen uptake, DCs undergo a maturation process initiated by i.e. inflammatory cytokines, co stimulatory molecules, bacterial or viral products, and migrate to the draining lymph node to pres ent the processed antigens to T cells $[3,4]$. Of note, DCs at different maturation stages produce distinct chemokine expression pattern which enables them to actively orchestrate the immune response by sequentially attracting innate and adaptive immune effectors. Under inflammatory conditions for instance, DCs are described to rapidly and transiently secrete mainly pro inflammatory chemo kines early during maturation, attracting other immature DCs as well as monocytes/macrophages [5]. Interestingly, recruited monocytes themselves can differentiate into DCs [6]. Later during maturation, DCs produce constitutive and homing chemokines

Abbreviations: MoDCs, monocyte-derived dendritic cells; $\mathrm{PGE}_{2}$, prostaglandin $\mathrm{E}_{2}$; CTL, cytotoxic T cell; NK cell, natural killer cell; fMLP, $N$-formyl-methionineleucine-phenylalanine.

* Corresponding author. Address: Biotechnology Institute Thurgau (BITg), University of Konstanz, Unterseestrasse 47, CH-8280 Kreuzlingen, Switzerland. Fax: +41716785021.
[5]. Upon challenging DCs with influenza viruses, three coordi nated successive waves of chemokine production were described [7]. In the first wave observed shortly after infection, chemokines are secreted that potently recruit neutrophils, cytotoxic $T$ cells (CTLs) and natural killer (NK) cells. In the second wave, chemo kines attracting effector memory cells are produced, while in the third wave occurring after full DC maturation homing chemokines are released that recruit naïve $\mathrm{T}$ and $\mathrm{B}$ cells [7]. Moreover, also the quality and magnitude of chemokine expression by DCs was shown to depend on the activation stimulus [8,9]. In addition, DCs also change their responsiveness to chemokines upon maturation. Maturing DCs loose their migratory response to inflammatory chemokines permitting the emigration from the inflamed tissue. Simultaneously, antigen loaded DCs up regulate surface expres sion of the lymph node homing chemokine receptor CCR7 [10 12]. It is well known that the environment in which DCs take up antigens and undergo maturation designates the quality of the immune response [4,13], presupposing that DCs can recognize distinct sources of activation [9]. We and others discovered that efficient CCR7 dependent DC migration requires prostaglandin $\mathrm{E}_{2}$ $\left(\mathrm{PGE}_{2}\right)$ early during maturation in vitro [14 16] and in vivo [17]. The arachidonic acid metabolite $\mathrm{PGE}_{2}$ is rapidly produced by many cell types in inflammation and has major functions in regulating immune responses [13]. Thereby, $\mathrm{PGE}_{2}$ participates in the outcome of adaptive $\mathrm{T}$ cell responses by regulating co stimulatory molecules [18], cytokines [14,19 23] and certain chemokines $[16,20,24$ 28]. 
Due to their natural function in orchestrating immune re sponses, human monocyte derived DCs (MoDCs) are widely used as cellular vaccines in immunotherapy [29 33] and the effective ness depends on their maturation state [34]. For the use of MoDCs in immunotherapies, different DC maturation protocols are contro versially discussed $[24,35,36]$. Depending on the maturation proto col used, the following biological function can be favored: DC migration [14,15], the capacity to stimulate $T$ cells [18,35 37] or the ability to recruit effector cells $[16,20]$. Nowadays, the majority of clinically approved MoDC maturation protocols contain either $\mathrm{PGE}_{2}$ [19] or IFN $\alpha$ [35] with different chemokine expression pat terns $[16,20,24,27,36]$. These studies either focused on distinct groups of chemokines regulated by $\mathrm{PGE}_{2}[16,24]$ or compared mat uration protocols in terms of their attracting capabilities [36]. However, there is no diversified study on the impact of $\mathrm{PGE}_{2}$ on chemokine expression in human MoDCs in combination with dif ferent maturation stimuli despite major implications in immune regulation and immunotherapy. Here, we provide a diversified study describing the influence of $\mathrm{PGE}_{2}$ on the production of a num ber of key chemokines by MoDCs matured with different stimuli mimicking various conditions of DC activation.

\section{Materials and methods}

\subsection{Generation of human MoDCs}

Human MoDCs were generated from whole blood of healthy do nors under serum free, clinically relevant conditions as previously described [15,18]. Briefly, peripheral blood mononuclear cells (PBMC) were isolated by density gradient centrifugation on Ficoll Paque Plus (Amersham Biosciences, Uppsala Sweden) and mono cytes were positively selected by using anti CD14 conjugated microbeads (Miltenyi Biotec, Bergisch Gladbach, Germany). Mono cytes were differentiated into immature MoDCs for 56 days in serum free AIM V medium (Gibco, Paisley, UK) supplemented with 50 ng/ml GM CSF and 50 ng/ml IL 4 (Peprotech, London, UK). Fully differentiated, immature DCs were harvested and matured for indi cated time points by adding $0.5 \mu \mathrm{g} / \mathrm{ml}$ soluble trimeric CD $40 \mathrm{~L}$ (sCD40L; PromoCell, Heidelberg, Germany), $20 \mu \mathrm{g} / \mathrm{ml}$ poly I:C (Sig ma, Saint Louis, MO), $10 \mu \mathrm{g} / \mathrm{ml}$ LPS (Salmonella abortus equi; Sigma) or a cocktail of cytokines including $20 \mathrm{ng} / \mathrm{ml} \mathrm{TNF} \alpha, 20 \mathrm{ng} / \mathrm{ml} \mathrm{IL} 6$ and $10 \mathrm{ng} / \mathrm{ml}$ IL $1 \beta$ (PeproTech, London, UK and PromoCell) in the presence or absence of $1 \mu \mathrm{g} / \mathrm{ml} \mathrm{PGE}_{2}$ (Minprostin ${ }^{\circledR} \mathrm{E} 2$, Pharma cia, Uppsala, Sweden) at a final cell density of $1 \times 10^{6}$ cells $/ \mathrm{ml}$. Blood donation for research purposes was approved by the ethics committee of Canton Thurgau and individual donors gave written consent.

\subsection{Quantitative real time $R T P C R$}

Total RNA of MoDCs was isolated using the RNeasy Mini Kit (Qiagen, Hilden, Germany) and transcribed into cDNA using random hexamer primers and the HiCapacity cDNA Reverse Transcription Kit (Applied Biosystems, Rotkreuz, Switzerland) according to the manufacturer's instructions. Amplification of human CCL2, CCL4, CCL5, CCL17, CCL22, CXCL8, CXCL10, CXCL13 and CXCL16 transcripts was performed using the Fast SYBR Green PCR Master Mix on a 7900HT Fast Real Time PCR System (Applied Biosystems) with an initial denaturation step at $95^{\circ}$ for $20 \mathrm{~s}$ followed by 40 cycles of $1 \mathrm{~s}$ at $95^{\circ} \mathrm{C}$ and $20 \mathrm{~s}$ at $60^{\circ} \mathrm{C}$. Forward and reverse primers were used at a concentration of $200 \mathrm{nM}$ with the following sequences: CCL2: 5' ACTCTCGCCTCCAGCATGAA, 5' TTGATTGCATCTGGCTGAGC; CCL4: 5' CGCCTGCTGCTTTTCTTACAC, 5' GGTTTGGAATACCACAGCTGG; CCL5: 5' GAGTATTTCTACACCAG TGGCAAGTG, 5' CCCGAACCCATTTCTTCTCTG or 5' GCCCACATCAA
GGAGTATTTCTACA, 5' CGGTTCTTTCGGGTGACAA; CCL 17: 5' GTCA CCGCCTGCTGATGG, 5' CCAGGGCCAGCATCTTCA; CCL20: 5' AAAAG TTGTCTGTGTGCGCAAA, 5' TTGGGCTATGTCCAATTCCATT; CCL22: 5' CTGCCGTGATTACGTCCGTTA, 5' TCCTTATCCCTGAAGGTTAGCAAC; CXCL8: 5' CCTTCCTGATTTCTGCAGCTCT, 5' GGTGGAAAGGTTTGGA GTATGTCT; CXCL10: 5' CCAGAATCGAAGGCCATCA, 5' CTCTGTGT GGTCCATCCTTGG; CXCL16: 5' CAACGAGGGCAGCGTCA, 5' AAAGG AGCTGGAACCTCGTGT. For amplification of human CCL19 mRNA and for verification of CCL5 mRNA expression the following Taq $\operatorname{man}^{\circledR}$ Gene Expression Arrays (Applied Biosystems) with identical thermal conditions were used: CCL19: Hs00171149_m1; CCL5 Hs99999048_m1. The mRNA expression was normalized to the house keeping genes $B 2$ microglobulin (B2M; primers: 5' GCTATC CAGCGTACTCCAAAGATTC and 5' CAACTTCAATGTCGGATGGATGA) and ubiquitin $C$ (UBC, primers $5^{\prime}$ ATTTGGGTCGCGGTTCTTG and $5^{\prime}$ TGCCTTGACATTCTCGATGGT) using Fast SYBR Green PCR Master Mix (Applied Biosystems). The mRNA expression was calculated by the $\Delta \Delta C t$ method and depicted as relative expression to immature DCs.

\subsection{Cytokine production}

Supernatants of terminally differentiated, immature MoDCs and MoDCs matured for $48 \mathrm{~h}$ from the same donor were centrifuged and stored at $80^{\circ} \mathrm{C}$. The amount of soluble chemokines was quantified using Human Quantikine ELISA Kits (R\&D Systems, Min neapolis MN) specific for CCL2, CCL4, CCL5, CCL17, CCL20, CCL22, CXCL8, CXCL10, CXCL13 and CXCL16. Concentrations of human CCL19 in supernatants were detected by sandwich ELISA. Briefly, MaxiSorp ELISA plates (Nunc, Roskilde, Denmark) were coated overnight with $5 \mu \mathrm{g} / \mathrm{ml}$ anti human CCL19/MIP $3 \beta$ capture anti body (\#AF361; R\&D Systems) in $100 \mu \mathrm{l}$ PBS at $4{ }^{\circ} \mathrm{C}$ followed by washing (0.02\% Tween 20 in PBS) and blocking with 3\% bovine serum albumin (BSA) in PBS for $1 \mathrm{~h}$ at room temperature. DC supernatants $(100 \mu \mathrm{l})$ were added to the wells, incubated for $1 \mathrm{~h}$, washed and incubated with $2.5 \mu \mathrm{g} / \mathrm{ml}$ biotinylated anti CCL19/ MIP $3 \beta$ antibody (\#BAF361; R\&D Systems) in $100 \mu \mathrm{lBS} / 3 \%$ BSA for $1 \mathrm{~h}$. Subsequently, plates were washed and incubated with a 1:200 dilution of streptavidin horseradish peroxidase (R\&D Systems) in PBS/3\% BSA. After washing, plates were incubated with $100 \mu \mathrm{l} 3,3^{\prime}, 5,5^{\prime}$ tetramethylbenzidine (Sigma), the reaction was stopped with $50 \mu \mathrm{l}$ of $1 \mathrm{M} \mathrm{H}_{2} \mathrm{SO}_{4}$ and absorbance was measured at $450 \mathrm{~nm}$. Graded amounts of recombinant human CCL19 (Pepro tech) were used as standards. Evaluation of ELISA data was assessed using Magellan ${ }^{\mathrm{TM}}$ Data Analysis Software (Tecan Group Ltd., Switzerland).

\subsection{Statistical evaluation}

Statistical analysis of samples treated with or without $\mathrm{PGE}_{2}$ was performed using GraphPad InStat (GraphPad Software Inc., La Jolla, CA) applying the Student's paired $t$ test. Protein concentrations above the upper detection limit were excluded from statistical analysis.

\section{Results}

DCs are known to be a rich source of chemokines and, impor tantly, differentially change the chemokine production pattern depending on the stimuli and the maturation stage. To determine the influence of $\mathrm{PGE}_{2}$ on MoDC chemokine expression patterns, we generated human MoDCs under serum free, clinically relevant conditions and matured them with either the TLR3 ligand poly I:C, the TLR4 ligand LPS, the cytokine cocktail consisting of IL 6, IL $1 \beta$ and TNF $\alpha$ (CC), or with soluble trimeric CD40 ligand (sCD40L), in 
the presence or absence of $\mathrm{PGE}_{2}$. Flow cytometric control experi ments revealed that monocytes fully differentiated into MoDCs (by losing CD14 staining), that MoDCs expressed the markers HLA DR, CD80 and CD86 and up regulated CCR7 and CD83 upon maturation as expected (data not shown) and as described previ ously $[15,18]$. Chemokine mRNA expression of MoDCs was deter mined by quantitative real time RT PCR after differentiation (immature DCs) as well as $6 \mathrm{~h}$ or $1 \mathrm{~d}$ after addition of different mat uration stimuli and mRNA expression is depicted in relation to immature DCs. Secretion of chemokine proteins into the culture supernatant was measured by ELISA after $2 \mathrm{~d}$ of maturation of fully differentiated MoDCs. We first investigated the role of $\mathrm{PGE}_{2}$ in modulating the expression pattern of chemokines primarily in volved in the recruitment of immediate immune effectors. The inflammatory chemokine CCL4 (MIP $1 \beta$ ) was shown to be ex pressed by DCs upon maturation and attracts monocytes, imma ture DCs, NK cells, as well as various $\mathrm{T}$ cell subsets via the chemokine receptor CCR5 $[10,26,38,39]$. As depicted in Fig. 1A, CCL4 mRNA was strongly expressed in human MoDCs within the first hours of maturation and its expression rapidly declined inde pendent of the maturation stimulus used. The presence of $\mathrm{PGE}_{2}$ led to a significant down regulation of CCL4 mRNA (mean values of relative mRNA expression in arbitrary units reduced by $\mathrm{PGE}_{2}$ : from 106 to 53 (poly I:C), 56 to 8.5 (CC), 222 to 34 (LPS) and 33 to 11 (sCD40L) after $6 \mathrm{~h}$ of maturation or 3.7 to 0.16 (poly I:C), 1.9 to 0.07 (CC), 20 to 0.24 (LPS) and 0.7 to 0.15 (sCD40L) after $1 \mathrm{~d}$ of mat uration), substantiated by a $\mathrm{PGE}_{2}$ mediated decrease in protein expression (protein concentration in $\mathrm{ng} / \mathrm{ml}$ : from $\geqslant 41$ to 20 (poly I:C), from $\geqslant 41$ to 8.35 .5 (CC), from $\geqslant 41$ to 172.2 (LPS), or $\geqslant 41$ 0.2 to 8.22 .1 (sCD40L)) (Fig. $1 \mathrm{~A}$ ), confirming previous results in murine LPS matured BMDCs [26]. A sustained mRNA expression of CCL5 (RANTES) was measured in MoDCs matured with either sCD40L, poly I:C or LPS (mean values: 16,362 or $458(6 \mathrm{~h}) ; 11$, 320 or 464 ( $1 \mathrm{~d})$, respectively), but CCL5 mRNA levels strongly de creased within $1 \mathrm{~d}$ of maturation with inflammatory cytokines (mean values: 251 (6 h) and 47 (1 d)) (Fig. 1A). CCL5 protein levels in SCD40L matured MoDCs were below the detection limit. The presence of $\mathrm{PGE}_{2}$ during maturation decreased CCL5 mRNA expres sion and protein secretion after TLR3 and TLR4 activation (mean values: 362 in the absence ( $\left.\mathrm{PGE}_{2}\right)$ to 320 in the presence of $\mathrm{PGE}_{2}\left(+\mathrm{PGE}_{2}\right)(6 \mathrm{~h}), 320186(1 \mathrm{~d})$ (poly I:C) or $458254(6 \mathrm{~h})$, 46597 (1 d) (LPS) and protein secretion from $\geqslant 4116\left(\mathrm{PGE}_{2}\right)$ to $219.5\left(+\mathrm{PGE}_{2}\right)$ for poly I:C or $\geqslant 414.3$ to $2.20 \mathrm{ng} / \mathrm{ml}$ for LPS matured MoDCs)(Fig. 1A). Interestingly, poly I:C and LPS ma tured MoDCs produced the highest concentrations of CCL5 which was reduced in presence of $\mathrm{PGE}_{2}$ (Fig. 1A). Expression of CCL2 (MCP 1) was detected early after MoDC stimulation (Fig. 1A) and was dampened or fully inhibited by $\mathrm{PGE}_{2}$ on both mRNA (to mean values from $41\left(\mathrm{PGE}_{2}\right)$ to $5.2(6 \mathrm{~h})\left(+\mathrm{PGE}_{2}\right), 10$ to $0.1(1 \mathrm{~d})$ for poly I:C ; 13 to $0.3(6 \mathrm{~h}), 3.4$ to $0.1(1 \mathrm{~d})$ for CC ; 47 to $0.4(6 \mathrm{~h}), 7.6$ to $0.03(1 \mathrm{~d})$ for LPS ; 11 to $1.1(6 \mathrm{~h}), 0.7$ to $0.5(1 \mathrm{~d})$ for sCD40L ma tured DCs) and protein levels (from $2011\left(\mathrm{PGE}_{2}\right)$ to 2.31 .1 $\left(+\mathrm{PGE}_{2}\right.$ ) for poly I:C , 4.40 .2 to 0.40 for CC , 194.2 to 0.20 for LPS and 100.4 to $130.3 \mathrm{ng} / \mathrm{ml}$ for sCD40L matured MoDCs) (Fig. 1A).

Upon viral infection, DCs were reported to express and rapidly secrete CXCL8 (IL 8) [7] thereby attracting granulocytes via CXCR1 and CXCR2 [40]. We observed an early and robust induction of CXCL8 transcription and protein secretion under all maturation conditions (Fig. 1B). Interestingly, $\mathrm{PGE}_{2}$ up regulated CXCL8 pro duction in stimulated MoDCs, except for TLR4 activated DCs where $\mathrm{PGE}_{2}$ down regulated CXCL8 production after one day of matura tion (to mean values from $121\left(\mathrm{PGE}_{2}\right)$ to $224\left(+\mathrm{PGE}_{2}\right)(6 \mathrm{~h}), 19$ to 23 ( $1 \mathrm{~d}$ ) for poly I:C ; 1013 to $1562(6 \mathrm{~h}), 32$ to 52 (1 d) for CC ; 1246 to $1315(6 \mathrm{~h}), 517$ to 147 ( $1 \mathrm{~d})$ for LPS ; 61 to 156 $(6 \mathrm{~h}), 1.5$ to $4.5(1 \mathrm{~d})$ for sCD40L and protein secretion from 1973 to 47129 for poly I:C , 0.3166 to 48269 for CC, 139 531 to 104191 for LPS and 036 to $051 \mathrm{ng} / \mathrm{ml}$ for sCD40L matured MoDCs) (Fig. 1B).

Upon activation, DCs were also reported to attract immune effectors harboring the chemokine receptor CXCR6 [7], such as NK T cells, Th1 cells and CTLs [41] by the production of the soluble
A

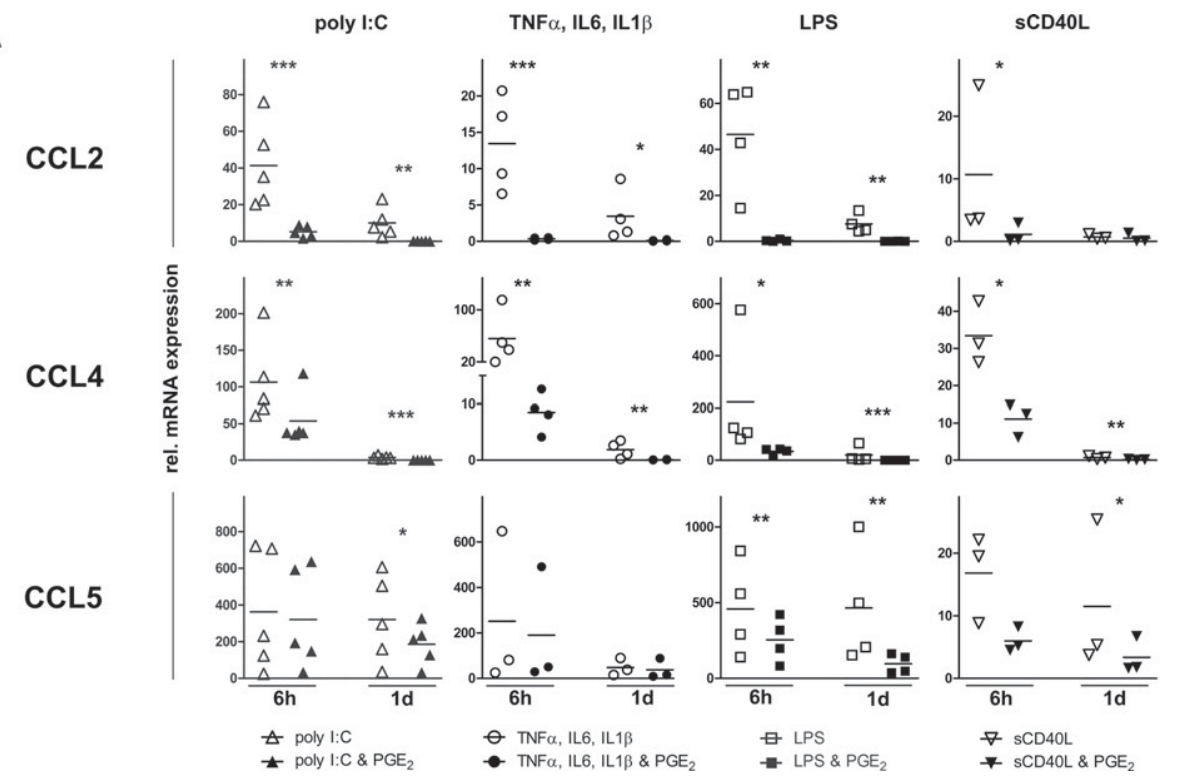

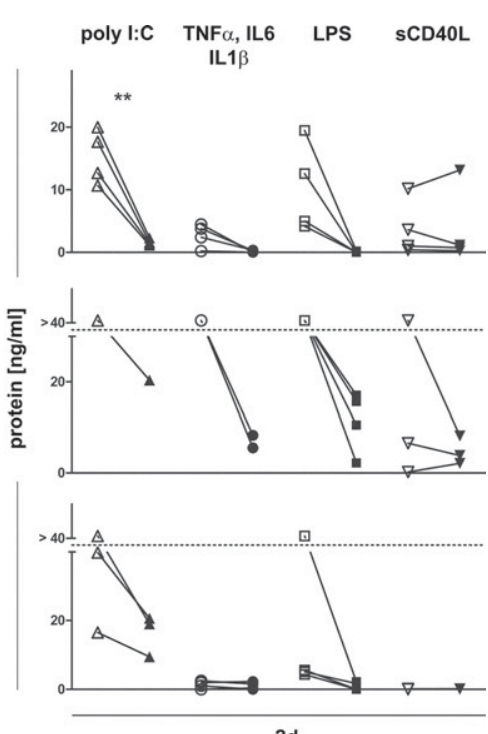

$2 d$

Fig. 1. Modulation of chemokine expression patterns of human MoDCs by PGE 2 . Human peripheral blood monocytes were differentiated to immature MoDCs for $5-6$ days in the presence of GM-CSF and IL-4. Immature MoDCs were stimulated with different maturation stimuli for indicated time points in the absence (open symbols) or presence (closed symbols) of $\mathrm{PGE}_{2}$. (left panel) Chemokine mRNA levels after $6 \mathrm{~h}$ and $1 \mathrm{~d}$ of maturation were determined by quantitative real-time RT-PCR and are depicted as relative expression to immature DCs. Mean values and SEM from 3 to 5 individual donors is depicted. (right panel) Supernatants of terminally differentiated, immature MoDCs and of MoDCs matured for $2 \mathrm{~d}$ derived from four individual donors were collected and chemokine protein secretion was assessed by specific ELISA. Chemokine concentrations above the upper limit are described with the upper detection limit (i.e., $>40 \mathrm{ng} / \mathrm{ml}$ ). Donors, where both values exceeded the detection limit were excluded. Concentrations below the detection limit were considered as $0 \mathrm{ng} / \mathrm{ml} .{ }^{*} p<0.05 ;{ }^{* *} p<0.01 ;{ }^{* * *} p<0.001$ by students two tailed paired $t$-test. 
B

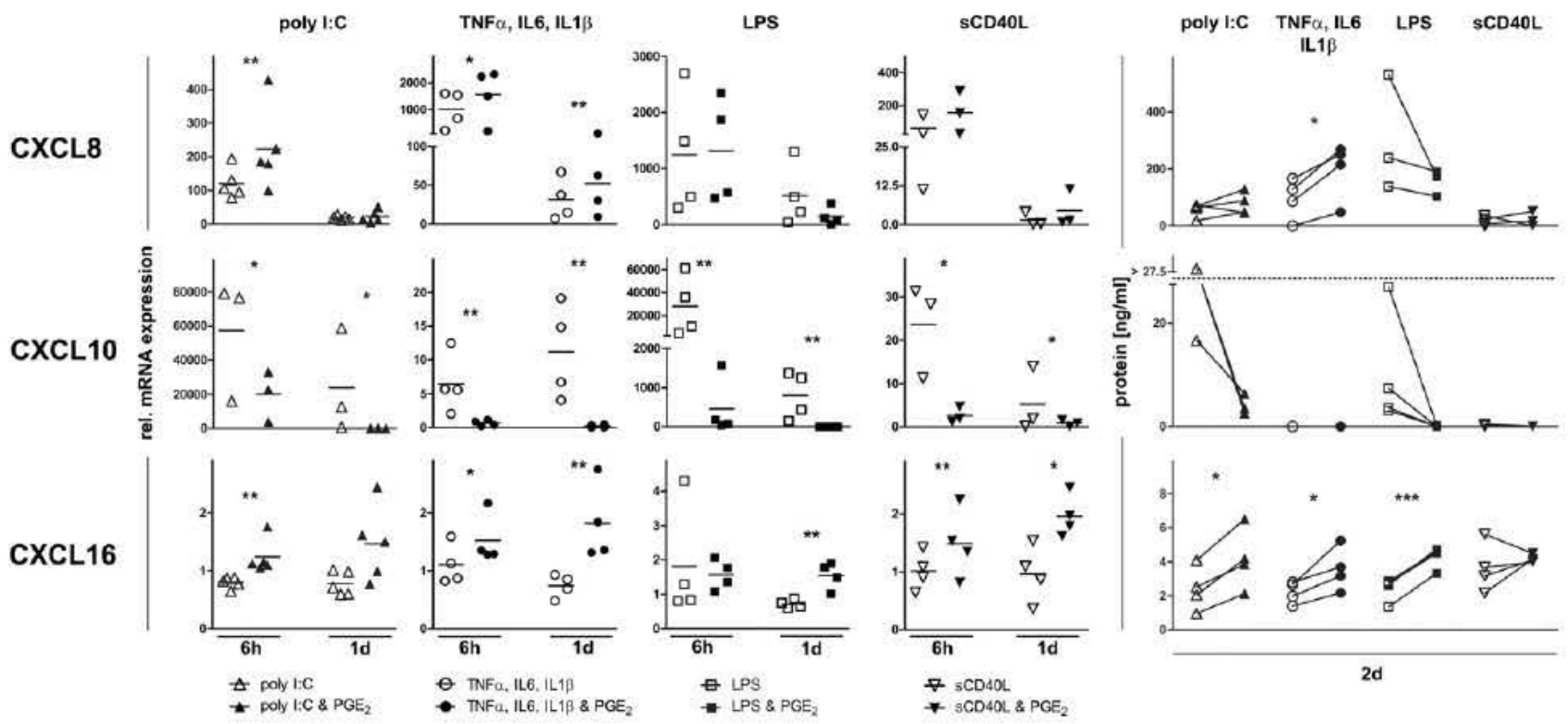

C

CCL17

CCL22

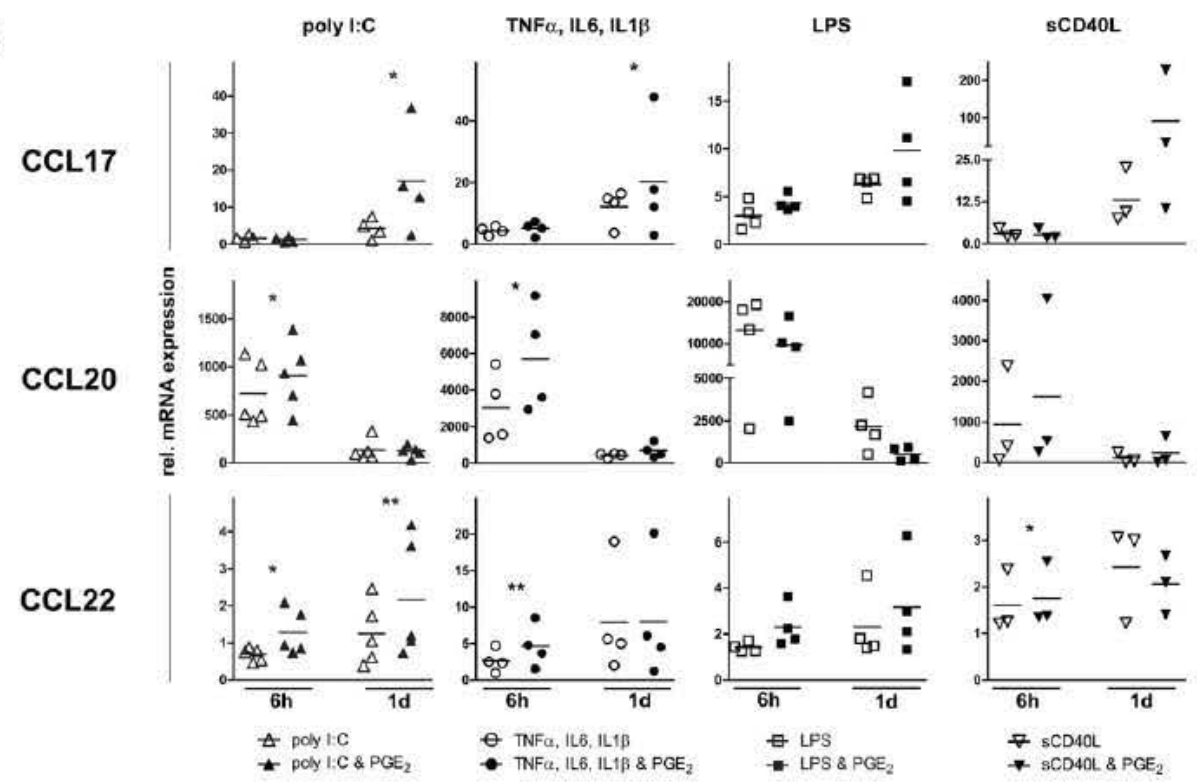

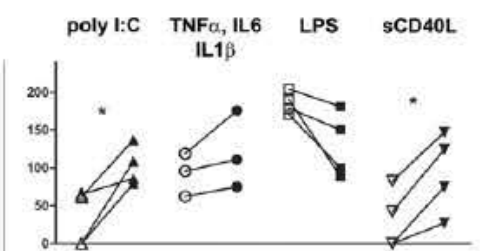
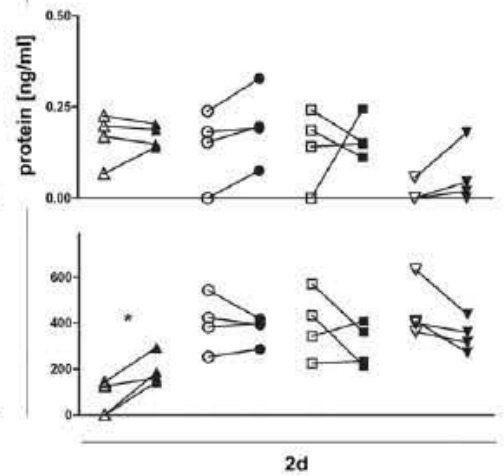

D

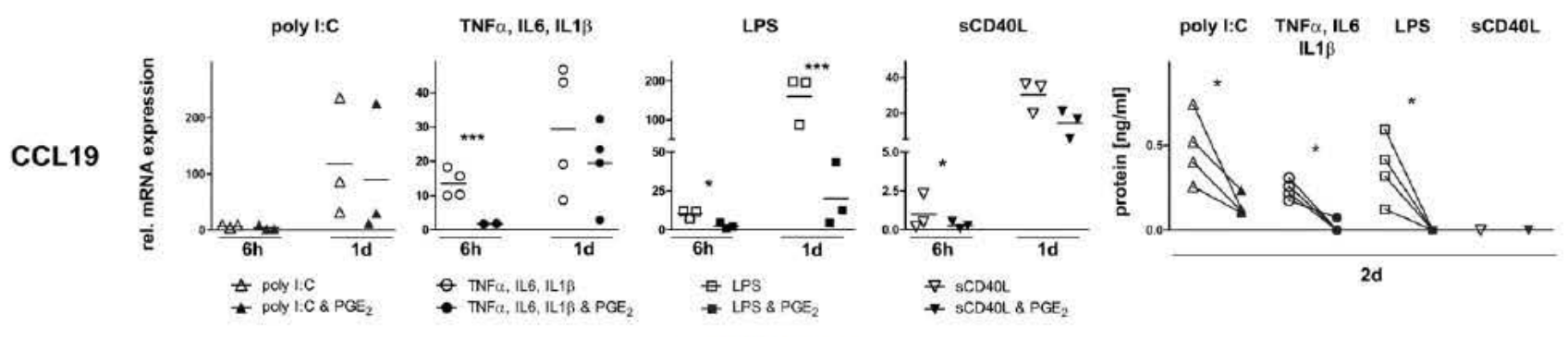

Fig. 1 (continued)

form of CXCL16 [42]. As shown in Fig. 1B, activated MoDCs consti tutively expressed and secreted CXCL16, which was significantly increased by $\mathrm{PGE}_{2}$ (to mean values from $0.8\left(\mathrm{PGE}_{2}\right)$ to 1.2 $\left(+\mathrm{PGE}_{2}\right)(6 \mathrm{~h}), 0.8$ to 1.5 ( $1 \mathrm{~d}$ ) for poly I:C ; 1.1 to $1.5(6 \mathrm{~h}), 0.7$ to
1.8 ( $1 \mathrm{~d}$ ) for CC ; 1.8 to $1.6(6 \mathrm{~h}), 0.7$ to 1.5 ( $1 \mathrm{~d}$ ) for LPS ; 1.0 to $1.5(6 \mathrm{~h}), 1.0$ to $2.0(1 \mathrm{~d})$ for SCD40L and protein secretion from 14 to 2.16 .5 for poly I:C , 1.42 .8 to 2.25 .2 for CC , 1.32 .8 to 3.34 .7 for LPS and 2.25 .6 to $4.04 .5 \mathrm{ng} / \mathrm{ml}$ for SCD $40 \mathrm{~L}$ matured 
MoDCs. Matured MoDCs also expressed the membrane anchored form of CXCL16, however, we did not observe obvious surface expression changes of CXCL16 by $\mathrm{PGE}_{2}$ (data not shown).

After establishing a first line of defense, maturing DCs were shown to release the CXCR3 ligands CXCR9 (MIG), CXCR10 (IP 10) and CXCR11 (I TAC) to attract Th1 and effector memory T cells $[7,24]$. Upon TLR3 or TLR4 ligation on human MoDCs, we detected a dramatic increase of CXCL10 transcripts within the first hours of maturation (Fig. 1B). Stimulation of MoDCs with inflammatory cytokines or SCD40L also induced CXCL10 mRNA expression but to a lesser extend compared to TLR stimulated MoDCs. CXCL10 mRNA expression was significantly dampened by $\mathrm{PGE}_{2}$ for all mat uration stimuli (to mean values from $57291\left(\mathrm{PGE}_{2}\right)$ to 20034 $\left(+\mathrm{PGE}_{2}\right)(6 \mathrm{~h}), 23986$ to 36 ( $1 \mathrm{~d}$ ) for poly I:C ; 6.5 to 0.7 (6 h), 11 to 0.2 ( $1 \mathrm{~d}$ ) for CC ; 28071 to 459 ( $6 \mathrm{~h}$ ), 800 to 0.7 (1 d) for LPS ; 24 to $2.6(6 \mathrm{~h}), 5.3$ to $0.8(1 \mathrm{~d})$ for $\mathrm{sCD} 40 \mathrm{~L}$ matured MoDCs) (Fig. 1B). These findings were confirmed on CXCL10 protein levels (protein secretion decreased by $\mathrm{PGE}_{2}$ from $\geqslant 2817$ to 2.66 .4 for poly I:C , 273.7 to 00.3 for LPS and 0.080 .5 to $0 \mathrm{ng} / \mathrm{ml}$ for sCD40L matured MoDCs) (Fig. 1B).

Next, we investigated the expression of inflammatory and homeostatic CCL20 (MIP 3 $\alpha /$ LARC) in MoDCs, a chemokine induced early upon maturation and known to attract various $\mathrm{T}$ cell and DC subsets expressing CCR6 [12,43 45]. PGE 2 significantly increased early CCL20 expression if MoDCs were matured with poly I:C or inflammatory cytokines (mean values of rel. mRNA expression from $717\left(\mathrm{PGE}_{2}\right)$ to $906\left(+\mathrm{PGE}_{2}\right)(6 \mathrm{~h}), 133$ to $122(1 \mathrm{~d})$ for poly I:C ; 3043 to 5701 ( 6 h), 430 to 699 (1 d) for CC and protein concentra tions from 0.170 .23 to 0.140 .2 for poly I:C, and 00.24 to 0.08 $0.32 \mathrm{ng} / \mathrm{ml}$ for CC matured MoDCs), whereas in SCD40L stimulated MoDCs the increase was not significant (from $941\left(\mathrm{PGE}_{2}\right)$ to 1607 $\left(+\mathrm{PGE}_{2}\right)(6 \mathrm{~h}), 97$ to 238 ( $1 \mathrm{~d}$ ) with protein concentrations from 0 0.06 to $00.18 \mathrm{ng} / \mathrm{ml}$ ). Despite an initial increase of CCL20 mRNA expression after $6 \mathrm{~h}$ in poly $\mathrm{I}: \mathrm{C}$ matured MoDCs, $\mathrm{PGE}_{2}$ decreased CCL20 protein concentrations in the majority of tested donors (pro tein concentrations: from 0.070 .23 to $0.140 .2 \mathrm{ng} / \mathrm{ml}$ ). In contrast, $\mathrm{PGE}_{2}$ insignificantly decreased CCL20 expression in LPS stimulated MoDCs (mean values of rel. mRNA expression from 13182 to 9619 $(6 \mathrm{~h}), 2147$ to $526(1 \mathrm{~d})$ and protein concentrations from 00.24 to $0.110 .24 \mathrm{ng} / \mathrm{ml}$ ) (Fig. 1C). We also investigated the family of lym phoid organ associated homeostatic chemokines. CCL17 (TARC) and CCL22 (MDC) were shown to be constitutively expressed by DCs and to bind to CCR4 on T helper cell subsets, including Th17 cells, and regulatory T cells [24,28,46 49]. As expected, MoDCs con stitutively expressed high amounts of CCL22 in response to SCD40L, poly I:C, LPS or inflammatory cytokine stimulation (Fig. 1C). PGE $_{2}$ slightly, but significantly induced CCL22 transcription mainly early during maturation (to mean values from $0.7\left(\mathrm{PGE}_{2}\right)$ to $1.3\left(+\mathrm{PGE}_{2}\right)$ $(6 \mathrm{~h}), 1.2$ to $2.2(1 \mathrm{~d})$ for poly I:C ; 2.4 to $4.6(6 \mathrm{~h}), 7.9$ to $8.0(1 \mathrm{~d})$ for CC ; 1.4 to 2.3 ( $6 \mathrm{~h}$ ), 2.3 to 3.2 ( $1 \mathrm{~d}$ ) for LPS ; 1.6 to $1.8(6 \mathrm{~h}), 2.4$ to 2.1 (1 d) for sCD40L matured MoDCs). Significantly increased CCL22 secretion by $\mathrm{PGE}_{2}$ was only observed in MoDCs matured with poly I:C, whereas MoDCs matured with the other stimuli secrete substantial amounts of CCL22 independently on the presence of $\mathrm{PGE}_{2}$ (from $0144\left(\mathrm{PGE}_{2}\right)$ to $161294\left(+\mathrm{PGE}_{2}\right)$ for poly I:C , 253 542 to 287418 for CC , 224570 to 214408 for LPS and 360 632 to $271437 \mathrm{ng} / \mathrm{ml}$ for sCD40L matured MoDCs) (Fig. 1C). Of note, in MoDCs matured solely by TNF $\alpha, \mathrm{PGE}_{2}$ was shown to either decreased [20] or increased [24] CCL22 expression, whereas in MoDCs matured with IFN $\alpha$ and TNF $\alpha$, PGE 2 did not regulate CCL22 transcription [24]. In line with other reports using only TNF $\alpha$ matured DCs [20], our results demonstrate that $\mathrm{PGE}_{2}$ in creased CCL17 mRNA expression in the first $24 \mathrm{~h}$ of maturation and independent of the stimulus (Fig. 1C) maturation (to mean val ues from 1.6 ( $\left.\mathrm{PGE}_{2}\right)$ to $1.3\left(+\mathrm{PGE}_{2}\right)(6 \mathrm{~h}), 4.3$ to $17(1 \mathrm{~d})$ for poly I:C ; 4.4 to 5.2 (6 h), 12 to 20 ( $1 \mathrm{~d}$ ) for CC ; 3.0 to 4.2 (6 h), 6.3 to 9.8
(1 d) for LPS ; 3.0 to 2.6 ( $6 \mathrm{~h}$ ), 13 to 91 ( $1 \mathrm{~d}$ ) for SCD40L matured MoDCs) However, we could detect a $\mathrm{PGE}_{2}$ dependent, elevated CCL17 secretion in poly I:C, sCD40L and in inflammatory cytokine matured MoDCs (protein secretion modulated by $\mathrm{PGE}_{2}$ from 066 to 80137 for poly I:C , 63119 to 75176 for CC , 171204 to 89181 for LPS and 083 to $27147 \mathrm{ng} / \mathrm{ml}$ for sCD40L matured MoDCs) (Fig. 1C).

Finally, DC derived CCL19 (ELC/MIP $3 \beta$ ) was suggested to re cruit naïve $\mathrm{T}$ cells at the early $\mathrm{T}$ cell priming phase to increase the frequency of $\mathrm{DC} T$ cell interactions, whereat $\mathrm{PGE}_{2}$ was reported to down regulate CCL19 in type 1 polarized MoDCs [16]. In our experiments, we observed that MoDCs transcribed CCL19 exclu sively at late TLR or cytokine induced maturation stages and that $\mathrm{PGE}_{2}$ dampened the expression of CCL19 (to mean values from 7.4 $\left(\mathrm{PGE}_{2}\right)$ to $4.7\left(+\mathrm{PGE}_{2}\right)(6 \mathrm{~h}), 118$ to $89(1 \mathrm{~d})$ for poly I:C ; 14 to 1.8 ( $6 \mathrm{~h}), 29$ to 19 ( $1 \mathrm{~d}$ ) for CC ; 10 to $2.5(6 \mathrm{~h}), 161$ to 20 (1 d) for LPS ; 1.0 to $0.3(6 \mathrm{~h}), 30$ to $14(1 \mathrm{~d})$ for sCD40L matured MoDCs) (Fig. 1D). TLR3 activated MoDCs produced the highest amount of CCL19 with detectable amounts in supernatants of MoDCs matured in presence of $\mathrm{PGE}_{2}$, whereas chemokine secretion in supernatants of SCD40L matured MoDCs was undetectable (protein secretion: $0.260 .74\left(\mathrm{PGE}_{2}\right)$ to $0.10 .2\left(+\mathrm{PGE}_{2}\right)$ for poly I:C , 0.220 .3 to 0 0.07 for CC , 0.120 .6 to $0 \mathrm{ng} / \mathrm{ml}$ for LPS matured MoDCs) (Fig. 1D).

\section{Discussion}

Understanding mechanisms that regulate DC behavior and the outcome of an adaptive immune response is still a central question in immunology. Divergent maturation signals and mediators, like $\mathrm{PGE}_{2}$, from the environment shape DC functions resulting in dis tinct adaptive immune response. $\mathrm{PGE}_{2}$ is an important lipid medi ator involved in many biological processes and represents a key player in the regulation of the immune system [13]. Depending on context and environment, $\mathrm{PGE}_{2}$ can promote or dampen im mune responses $[13,50]$. $\mathrm{PGE}_{2}$ production is highly induced upon infection or inflammation and accounts for the classical symptoms of swelling, redness, vasodilatation and pain [13]. As exemplified for viral infection, DCs are among the first cells to arrive at the virus entry sites. They take up antigens and subsequently orches trate the immune response by their ability to attract further im mune effectors [7]. In the present study, we show an increased expression of the neutrophil and NK cell attracting chemokine CXCL8 within the first hours of MoDC maturation, which is in line with other observations [7]. We report for the first time that $\mathrm{PGE}_{2}$ increases CXCL8 expression in MoDCs matured with inflammatory cytokines, poly I:C or SCD40L, but not if MoDCs are challenged with LPS. For the latter, it is tempting to speculate that this phenomenon displays a negative feedback regulation as bacterial pathogens themselves are a rich source of the formyl peptide fMLP that at tracts neutrophils [51]. Moreover, we discovered a continuous in crease of CXCL16 expression by MoDCs in the presence of $\mathrm{PGE}_{2}$ which augments immigration of CXCR6 expressing NK T cells, naïve CTLS and a subset of T helper cells into inflamed tissue or sec ondary lymphoid organs. In contrast, we found that the presence of $\mathrm{PGE}_{2}$ led to a strong down regulation of the pro inflammatory che mokines CCL2, CCL4, CCL5 and CXCL10. As a consequence, PGE $\mathrm{im}_{2}$ pairs the attraction of cells expressing CCR2, such as neutrophils, monocytes, immature DCs, NK cells and T cell subsets that are in volved in early immune responses [48,52] as well as immune effec tors expressing CCR5. Moreover, the impaired ability to attract important immune effectors, such as monocytes, immature DCs or effector T cell subsets, supports the notion that $\mathrm{PGE}_{2}$ might in duce an anti inflammatory behavior of DCs $[24,26,53]$. Moreover, our data suggest that $\mathrm{PGE}_{2}$ alters the recruitment ability of DCs to attract specific immune effectors, probably to prevent excessive adaptive immune responses, but favors the attraction of primarily 
innate immune effectors such as neutrophils and NK cells through elevating the expression of CXCL8 and CXCL16. Furthermore, we detected a DC maturation stimulus dependent regulation of the homeostatic chemokines CCL17, CCL20 and CCL22 by PGE 2 . In an earlier study, $\mathrm{PGE}_{2}$ was shown to up regulate CCL22 mRNA expres sion in human immature DCs [47] and DCs matured with TNF $\alpha$ alone $[24,47]$. The authors therefore suggested that addition of $\mathrm{PGE}_{2}$ to the maturation stimulus of DCs prepared for immunother apies increased the ability of DCs to interact with regulatory T cells [24]. In contrast, another study showed that using the same condi tion, $\mathrm{PGE}_{2}$ down regulated CCL22 expression [20], whereas DCs matured by TNF $\alpha$ in combination with IFN $\alpha$ [24] or in combination with LPS and IL $1 \beta$ [48] expressed similar amounts of CCL22 inde pendently on the presence of $\mathrm{PGE}_{2}$. Latter is in line with our data indicating that CCL22 was constitutively expressed in MoDCs ma tured by all four stimuli tested, and that $\mathrm{PGE}_{2}$ did not substantially change the expression profile. Intriguingly, the homeostatic che mokines CCL17, CCL20 and CCL22 can attract FOXP3 ${ }^{+}$regulatory $\mathrm{T}$ cells as well as Th17 cells which share a similar receptor expres sion pattern [49]. This is of interest because Th17 cells play key roles in several $\mathrm{PGE}_{2}$ mediated autoimmune diseases [54] and were shown to promote CTL activation in tumor immunity [55]. For the latter, the use of $\mathrm{PGE}_{2}$ in clinical maturation protocols might offer beneficial perspectives. Furthermore, we corroborate recent findings [16] and provide further evidence that $\mathrm{PGE}_{2}$ down regulates CCL19 expression independent of the maturation stimulus. Of note, we found that MoDCs did not secret CCL21 (SLC/6Ckine) or CXCL12 (SDF 1). Interestingly, we were able to de tect a slight up regulation of the $\mathrm{B}$ cell attracting chemokine CXCL13 by PGE $_{2}$, enabling DCs to mediate $T$ cell dependent $B$ cell activation. Pilot experiments indicated that MoDCs matured by poly I:C produce low amounts of the $B$ and follicular $T$ helper cell attracting chemokine CXCL13 (BCA 1) exclusively in the presence of $\mathrm{PGE}_{2}$, whereas no CXCL13 production with other DC maturation stimuli suggesting different outcomes in B cell activation.

\section{Conclusion}

Our results reveal that $\mathrm{PGE}_{2}$ plays a pivotal role in modulating the pattern of chemokine expression by DCs undergoing matura tion and underscores the high plasticity of chemokine expression in human MoDCs in response to distinct stimuli. For instance, in MoDCs stimulated with inflammatory cytokines and upon TLR3 triggering, $\mathrm{PGE}_{2}$ rapidly (within $6 \mathrm{~h}$ ) up regulates the chemokines CXCL8 and CXCL16 known to recruit innate immune cells such as neutrophils and NK cells. Of note, up regulation of CXCL16 by $\mathrm{PGE}_{2}$ is persistent, leading to further attraction of CXCR6 express ing NK T cells, naïve CTLs and subsets of T helper cells. Moreover, $\mathrm{PGE}_{2}$ induces transcription of the homeostatic chemokines CCL17 and CCL22 dependent on the maturation stimuli. However, $\mathrm{PGE}_{2}$ suppresses expression of the inflammatory chemokines CCL2, CCL4 and CCL5, as well as CXCL10 early upon DC maturation as well as at later time points where DCs most likely arrived in lymph nodes and hence contributes to $\mathrm{T}$ cell differentiation during anti gen presentation.

\section{Acknowledgments}

We thank Marcus Groettrup and Michael Basler for helpful dis cussions, and Eva Maria Boneberg for technical advice. This study was supported in parts by research funding from the Swiss $\mathrm{Na}$ tional Science Foundation (SNF 31003A 127474/1), the Thurgaui sche Stiftung für Wissenschaft und Forschung, the Swiss State Secretariat for Education and Research, and the Thurgauische Krebsliga to DFL. DFL is a recipient of a career development award from the Prof. Dr. Max Cloëtta Foundation. The funding bodies had no role in study design, data collection and analysis, decision to publish, or preparation of the manuscript.

\section{References}

[1] C. Reis e Sousa, Dendritic cells in a mature age, Nat. Rev. Immunol. 6 (2006) 476-483.

[2] J. Banchereau, R.M. Steinman, Dendritic cells and the control of immunity, Nature 392 (1998) 245-252.

[3] D. Alvarez, E.H. Vollmann, U.H. von Andrian, Mechanisms and consequences of dendritic cell migration, Immunity 29 (2008) 325-342.

[4] P. Guermonprez, J. Valladeau, L. Zitvogel, C. Thery, S. Amigorena, Antigen presentation and T cell stimulation by dendritic cells, Annu. Rev. Immunol. 20 (2002) 621-667.

[5] F. Sallusto, B. Palermo, D. Lenig, M. Miettinen, S. Matikainen, I. Julkunen, R. Forster, R. Burgstahler, M. Lipp, A. Lanzavecchia, Distinct patterns and kinetics of chemokine production regulate dendritic cell function, Eur. J. Immunol. 29 (1999) 1617-1625.

[6] F. Geissmann, M.G. Manz, S. Jung, M.H. Sieweke, M. Merad, K. Ley, Development of monocytes, macrophages, and dendritic cells, Science 327 (2010) 656-661.

[7] B. Piqueras, J. Connolly, H. Freitas, A.K. Palucka, J. Banchereau, Upon viral exposure, myeloid and plasmacytoid dendritic cells produce 3 waves of distinct chemokines to recruit immune effectors, Blood 107 (2006) 2613-2618.

[8] Q. Huang, D. Liu, P. Majewski, L.C. Schulte, J.M. Korn, R.A. Young, E.S. Lander, N. Hacohen, The plasticity of dendritic cell responses to pathogens and their components, Science 294 (2001) 870-875.

[9] D. Jarrossay, G. Napolitani, M. Colonna, F. Sallusto, A. Lanzavecchia, Specialization and complementarity in microbial molecule recognition by human myeloid and plasmacytoid dendritic cells, Eur. J. Immunol. 31 (2001) 3388-3393.

[10] F. Sallusto, P. Schaerli, P. Loetscher, C. Schaniel, D. Lenig, C.R. Mackay, S. Qin, A. Lanzavecchia, Rapid and coordinated switch in chemokine receptor expression during dendritic cell maturation, Eur. J. Immunol. 28 (1998) 2760-2769.

[11] S. Sozzani, P. Allavena, G. D’Amico, W. Luini, G. Bianchi, M. Kataura, T. Imai, O. Yoshie, R. Bonecchi, A. Mantovani, Differential regulation of chemokine receptors during dendritic cell maturation: a model for their trafficking properties, J. Immunol. 161 (1998) 1083-1086.

[12] M.C. Dieu, B. Vanbervliet, A. Vicari, J.M. Bridon, E. Oldham, S. Ait-Yahia, F. Briere, A. Zlotnik, S. Lebecque, C. Caux, Selective recruitment of immature and mature dendritic cells by distinct chemokines expressed in different anatomic sites, J. Exp. Med. 188 (1998) 373-386.

[13] D.F. Legler, M. Bruckner, E. Uetz-von Allmen, P. Krause, Prostaglandin E(2) at new glance. Novel insights in functional diversity offer therapeutic chances, Int. J. Biochem. Cell Biol. 42 (2010) 198-201

[14] E. Scandella, Y. Men, S. Gillessen, R. Forster, M. Groettrup, Prostaglandin E2 is a key factor for CCR7 surface expression and migration of monocyte-derived dendritic cells, Blood 100 (2002) 1354-1361.

[15] D.F. Legler, P. Krause, E. Scandella, E. Singer, M. Groettrup, Prostaglandin E2 is generally required for human dendritic cell migration and exerts its effect via EP2 and EP4 receptors, J. Immunol. 176 (2006) 966-973.

[16] R. Muthuswamy, J. Mueller-Berghaus, U. Haberkorn, T.A. Reinhart, D. Schadendorf, P. Kalinski, PGE2 transiently enhances DC expression of CCR7 but inhibits the ability of DCs to produce CCL19 and attract naive T cells, Blood 116 (2010) 1454-1459.

[17] K. Kabashima, D. Sakata, M. Nagamachi, Y. Miyachi, K. Inaba, S. Narumiya, Prostaglandin E2-EP4 signaling initiates skin immune responses by promoting migration and maturation of Langerhans cells, Nat. Med. 9 (2003) 744-749.

[18] P. Krause, M. Bruckner, C. Uermosi, E. Singer, M. Groettrup, D.F. Legler, Prostaglandin E2 enhances T cell proliferation by inducing the co-stimulatory molecules OX40L, CD70 and 4-1BBL on dendritic cells, Blood 113 (2009) 2451-2460.

[19] H. Jonuleit, U. Kuhn, G. Muller, K. Steinbrink, L. Paragnik, E. Schmitt, J. Knop, A.H. Enk, Pro-inflammatory cytokines and prostaglandins induce maturation of potent immunostimulatory dendritic cells under fetal calf serum-free conditions, Eur. J. Immunol. 27 (1997) 3135-3142.

[20] M.T. Rubio, T.K. Means, R. Chakraverty, J. Shaffer, Y. Fudaba, M. Chittenden, A.D. Luster, M. Sykes, Maturation of human monocyte-derived dendritic cells (MoDCs) in the presence of prostaglandin E2 optimizes CD4 and CD8 T cellmediated responses to protein antigens: role of PGE2 in chemokine and cytokine expression by MoDCs, Int. Immunol. 17 (2005) 1561-1572.

[21] P. Kalinski, J.H. Schuitemaker, C.M. Hilkens, M.L. Kapsenberg, Prostaglandin E2 induces the final maturation of IL-12-deficient CD1a+CD83+ dendritic cells: the levels of IL-12 are determined during the final dendritic cell maturation and are resistant to further modulation, J. Immunol. 161 (1998) 2804-2809.

[22] T. Khayrullina, J.H. Yen, H. Jing, D. Ganea, In vitro differentiation of dendritic cells in the presence of prostaglandin E2 alters the IL-12/IL-23 balance and promotes differentiation of Th17 cells, J. Immunol. 181 (2008) 721-735.

[23] A.F. Sheibanie, I. Tadmori, H. Jing, E. Vassiliou, D. Ganea, Prostaglandin E2 induces IL-23 production in bone marrow-derived dendritic cells, FASEB J. 18 (2004) 1318-1320. 
[24] R. Muthuswamy, J. Urban, J.J. Lee, T.A. Reinhart, D. Bartlett, P. Kalinski, Ability of mature dendritic cells to interact with regulatory T cells is imprinted during maturation, Cancer Res. 68 (2008) 5972-5978.

[25] H. Jing, J.H. Yen, D. Ganea, A novel signaling pathway mediates the inhibition of CCL3/4 expression by prostaglandin E2, J. Biol. Chem. 279 (2004) 5517655186

[26] H. Jing, E. Vassiliou, D. Ganea, Prostaglandin E2 inhibits production of the inflammatory chemokines CCL3 and CCL4 in dendritic cells, J. Leukoc. Biol. 74 (2003) 868-879.

[27] J.L. Vissers, F.C. Hartgers, E. Lindhout, M.B. Teunissen, C.G. Figdor, G.J. Adema, Quantitative analysis of chemokine expression by dendritic cell subsets in vitro and in vivo, J. Leukoc. Biol. 69 (2001) 785-793.

[28] E. Kuroda, T. Sugiura, K. Okada, K. Zeki, U. Yamashita, Prostaglandin E2 upregulates macrophage-derived chemokine production but suppresses IFNinducible protein-10 production by APC, J. Immunol. 166 (2001) 1650-1658.

[29] G. Schuler, Dendritic cells in cancer immunotherapy, Eur. J. Immunol. 40 (2010) 2123-2130.

[30] A.K. Palucka, H. Ueno, J.W. Fay, J. Banchereau, Taming cancer by inducing immunity via dendritic cells, Immunol. Rev. 220 (2007) 129-150.

31] E. Gilboa, DC-based cancer vaccines, J. Clin. Invest. 117 (2007) 1195-1203.

[32] P.J. Tacken, I.J. de Vries, R. Torensma, C.G. Figdor, Dendritic-cell immunotherapy: from ex vivo loading to in vivo targeting, Nat. Rev. Immunol. 7 (2007) 790-802.

[33] J. Banchereau, A.K. Palucka, Dendritic cells as therapeutic vaccines against cancer, Nat. Rev. Immunol. 5 (2005) 296-306.

[34] I.J. de Vries, D.J. Krooshoop, N.M. Scharenborg, W.J. Lesterhuis, J.H. Diepstra, G.N. Van Muijen, S.P. Strijk, T.J. Ruers, O.C. Boerman, W.J. Oyen, G.J. Adema, C.J. Punt, C.G. Figdor, Effective migration of antigen-pulsed dendritic cells to lymph nodes in melanoma patients is determined by their maturation state, Cancer Res. 63 (2003) 12-17.

[35] R.B. Mailliard, A. Wankowicz-Kalinska, Q. Cai, A. Wesa, C.M. Hilkens, M.L Kapsenberg, J.M. Kirkwood, W.J. Storkus, P. Kalinski, Alpha-type-1 polarized dendritic cells: a novel immunization tool with optimized CTL-inducing activity, Cancer Res. 64 (2004) 5934-5937.

[36] I. Moller, K. Michel, N. Frech, M. Burger, D. Pfeifer, P. Frommolt H. Veelken, A.K. Thomas-Kaskel, Dendritic cell maturation with poly(I:C)-based versus PGE2based cytokine combinations results in differential functional characteristics relevant to clinical application, J. Immunother. 31 (2008) 506-519.

[37] P. Krause, E. Singer, P.I. Darley, J. Klebensberger, M. Groettrup, D.F. Legler, Prostaglandin E2 is a key factor for monocyte-derived dendritic cell maturation: enhanced T cell-stimulatory capacity despite IDO, J. Leukoc. Biol. 82 (2007) 1106-1114.

[38] F. Castellino, A.Y. Huang, G. Altan-Bonnet, S. Stoll, C. Scheinecker, R.N Germain, Chemokines enhance immunity by guiding naive CD8+ $\mathrm{T}$ cells to sites of CD4+ T cell-dendritic cell interaction, Nature 440 (2006) 890-895.

[39] F. Sallusto, E. Kremmer, B. Palermo, A. Hoy, P. Ponath, S. Qin, R. Forster, M. Lipp A. Lanzavecchia, Switch in chemokine receptor expression upon TCR stimulation reveals novel homing potential for recently activated $\mathrm{T}$ cells, Eur. J. Immunol. 29 (1999) 2037-2045.

[40] M.L. Scimone, V.P. Lutzky, S.I. Zittermann, P. Maffia, C. Jancic, F. Buzzola, A.C Issekutz, H.E. Chuluyan, Migration of polymorphonuclear leucocytes is influenced by dendritic cells, Immunology 114 (2005) 375-385.

[41] T. Shimaoka, T. Nakayama, N. Kume, S. Takahashi, J. Yamaguchi, M. Minami, K. Hayashida, T. Kita, J. Ohsumi, O. Yoshie, S. Yonehara, Cutting edge: SR-PSOX/
CXC chemokine ligand 16 mediates bacterial phagocytosis by APCs through its chemokine domain, J. Immunol. 171 (2003) 1647-1651.

[42] R. van der Voort, V. Verweij, T.M. de Witte, E. Lasonder, G.J. Adema, H. Dolstra, An alternatively spliced CXCL16 isoform expressed by dendritic cells is a secreted chemoattractant for CXCR6+ cells, J. Leukoc. Biol. (2010).

[43] D.N. Cook, D.M. Prosser, R. Forster, J. Zhang, N.A. Kuklin, S.J. Abbondanzo, X.D. Niu, S.C. Chen, D.J. Manfra, M.T. Wiekowski, L.M. Sullivan, S.R. Smith, H.B Greenberg, S.K. Narula, M. Lipp, S.A. Lira, CCR6 mediates dendritic cell localization, lymphocyte homeostasis, and immune responses in mucosal tissue, Immunity 12 (2000) 495-503.

[44] D.R. Greaves, W. Wang DJ. Dairaghi, M.C. Dieu, B. Saint-Vis, K. Franz-Bacon, D. Rossi, C. Caux, T. McClanahan, S. Gordon, A. Zlotnik, T.J. Schall, CCR6, a CC chemokine receptor that interacts with macrophage inflammatory protein 3alpha and is highly expressed in human dendritic cells, J. Exp. Med. 186 (1997) 837-844.

[45] K. Hirota, H. Yoshitomi, M. Hashimoto, S. Maeda, S. Teradaira, N. Sugimoto, T. Yamaguchi, T. Nomura, H. Ito, T. Nakamura, N. Sakaguchi, S. Sakaguchi, Preferential recruitment of CCR6-expressing Th17 cells to inflamed joints via CCL20 in rheumatoid arthritis and its animal model, J. Exp. Med. 204 (2007) 2803-2812.

[46] A. Iellem, M. Mariani, R. Lang, H. Recalde, P. Panina-Bordignon, F. Sinigaglia, D. D'Ambrosio, Unique chemotactic response profile and specific expression of chemokine receptors CCR4 and CCR8 by CD4(+)CD25(+) regulatory T cells, J. Exp. Med. 194 (2001) 847-853.

[47] A. Mcllroy, G. Caron, S. Blanchard, I. Fremaux, D. Duluc, Y. Delneste, A Chevailler, $\mathrm{P}$. Jeannin, Histamine and prostaglandin $\mathrm{E}$ up-regulate the production of Th2-attracting chemokines (CCL17 and CCL22) and downregulate IFN-gamma-induced CXCL10 production by immature human dendritic cells, Immunology 117 (2006) 507-516.

[48] M.C. Lebre, T. Burwell, P.L Vieira, J. Lora, A.J. Coyle, M.L. Kapsenberg B.E. Clausen, E.C. De Jong, Differential expression of inflammatory chemokines by Th1- and Th2-cell promoting dendritic cells: a role for different mature dendritic cell populations in attracting appropriate effector cells to peripheral sites of inflammation, Immunol. Cell Biol. 83 (2005) 525-535.

[49] H.W. Lim, J. Lee, P. Hillsamer, C.H. Kim, Human Th17 cells share major trafficking receptors with both polarized effector $\mathrm{T}$ cells and FOXP3+ regulatory T cells, J. Immunol. 180 (2008) 122-129.

[50] Y. Sugimoto, S. Narumiya, Prostaglandin E receptors, J. Biol. Chem. 282 (2007) $11613-11617$

[51] A. Bagorda, C.A. Parent, Eukaryotic chemotaxis at a glance, J. Cell Sci. 121 (2008) 2621-2624

[52] S. Sozzani, P. Allavena, A. Vecchi, A. Mantovani, The role of chemokines in the regulation of dendritic cell trafficking, J. Leukoc. Biol. 66 (1999) 1-9.

[53] E. Vassiliou, H. Jing. D. Ganea, Prostaglandin E2 inhibits TNF production in murine bone marrow-derived dendritic cells, Cell Immunol. 223 (2003) 120132.

[54] C. Yao, D. Sakata, Y. Esaki, Y. Li, T. Matsuoka, K. Kuroiwa, Y. Sugimoto, S Narumiya, Prostaglandin E(2)-EP4 signaling promotes immune inflammation through $\mathrm{T}(\mathrm{H}) 1$ cell differentiation and $\mathrm{T}(\mathrm{H}) 17$ cell expansion, Nat. Med. 15 (2009) 633-640.

[55] N. Martin-Orozco, P. Muranski, Y. Chung, X.O. Yang, T. Yamazaki, S. Lu, P. Hwu, N.P. Restifo, W.W. Overwijk, C. Dong, T helper 17 cells promote cytotoxic T cell activation in tumor immunity, Immunity 31 (2009) 787-798. 